\title{
Aa. Vv., Madame de Staël et le Groupe de Coppet. Le Groupe de Coppet face à l'esclavage; "De l'Allemagne" (1814-2014). Une mémoire au présent
}

\section{Catherine Thomas}

\section{(2) OpenEdition \\ Journals}

Édition électronique

URL : http://journals.openedition.org/studifrancesi/1371

DOI : 10.4000/studifrancesi. 1371

ISSN : 2421-5856

Éditeur

Rosenberg \& Sellier

\section{Édition imprimée}

Date de publication : 1 décembre 2015

Pagination : 601-602

ISSN : 0039-2944

\section{Référence électronique}

Catherine Thomas, «Aa. Vv., Madame de Staël et le Groupe de Coppet. Le Groupe de Coppet face à l'esclavage; "De l'Allemagne" (1814-2014). Une mémoire au présent », Studi Francesi [En ligne], 177 (LIX I III) | 2015, mis en ligne le 01 décembre 2015, consulté le 09 janvier 2021. URL : http://

journals.openedition.org/studifrancesi/1371 ; DOI : https://doi.org/10.4000/studifrancesi.1371

Ce document a été généré automatiquement le 9 janvier 2021.

\section{c)}

Studi Francesi è distribuita con Licenza Creative Commons Attribuzione - Non commerciale - Non opere derivate 4.0 Internazionale. 


\title{
Aa. Vv., Madame de Staël et le Groupe de Coppet. Le Groupe de Coppet face à l'esclavage; "De l'Allemagne" (1814-2014). Une mémoire au présent
}

\author{
Catherine Thomas
}

\section{RÉFÉRENCE}

AA. VV., Madame de Staël et le Groupe de Coppet. Le Groupe de Coppet face à l'esclavage; "De l'Allemagne” (1814-2014). Une mémoire au présent, 2014, «Cahiers staëliens», n. 64, pp. 216.

1 Le numéro 64 des «Cahiers staëliens» présente deux parties distinctes: la première rassemble les textes issus d'une journée d'étude interdisciplinaire sur l'engagement antiesclavagiste de Coppet, organisée au château de Coppet le 8 septembre 2013 par les sociétés staëlienne, constantienne et sismondienne, à l'initiative de l'Institut Benjamin Constant. La présentation de Léonard BURNAND (pp. 7-8) rappelle l'implication de Necker, de Mme de Staël et de ses enfants dans la lutte contre la traite des Noirs et précise que le sujet reste peu exploré, même si certains chercheurs en ont souligné l'intérêt. S'appuyant sur les archives privées d'Auguste, Léonard BURNAND (Abolir pour agir: l'engagement antiesclavagiste d'Auguste de Staël, pp.9-29) montre ensuite le rôle déterminant que joua le fils de Mme de Staël dans le mouvement abolitionniste français des années 1820: à la tête du Comité pour l'abolition de la traite des Noirs, constitué au sein de la Société de la Morale chrétienne, Auguste s'inspire du modèle anglais pour mobiliser le gouvernement et l'opinion publique à son combat: pétitions, plaidoirie auprès du dauphin, exposition d'instruments de contrainte rapportés d'une enquête menée à Nantes sur le trafic négrier illicite et publication des résultats de cette enquête ont certainement contribué à la promulgation de la loi du 25 avril 1827, qui induit un durcissement des sanctions à l'encontre des personnes reconnues coupables de 
commerce négrier, étape importante dans l'avancée d'un combat si cher au grand-père et à la mère d'Auguste. C'est ensuite la figure de Benjamin Constant qui est mise à l'honneur: tout en précisant la spécificité politique de son implication contre la traite, Frédéric JAUNIN (pp. 31-57) analyse les réactions aux discours qu'il prononça devant l'assemblée parlementaire entre juin 1821 et mars 1827 pour mieux comprendre les raisons de l'insuccès de son combat au Palais Bourbon, avant avril 1827. Stéphanie GENAND (Staël et l'Afrique: esthétique et politique de l'altérité, pp.59-76) se penche quant à elle sur la complexité de la question de l'esclavagisme chez Germaine de Staël, qui aborde le sujet à la fois dans des textes politiques, sa correspondance et trois œuvres de fiction. L'auteur montre la portée symbolique de l'engagement de l'écrivain, dans lequel s'inscrivent à la fois des valeurs familiales et sa propre lutte contre toute forme d'asservissement, notamment au sein du mariage. Rapprochant les personnages d'esclaves féminines créés dans les nouvelles et les figures de Corinne ou Delphine, S. Génand fait alors l'hypothèse d'une «identité inconsciemment africaine de G. de Staël» propre à éclairer sa conception des passions. Marcel Dorigny (pp. 77-92) aborde enfin les théories de Sismondi qui, dans un contexte de remise en question du colonialisme, apporte des arguments économiques à la lutte contre la traite des Noirs. Dans le sillage de la Société des Amis des Noirs, il prône une Nouvelle colonisation dont la prise d'Alger constitue, en France, la première étape: antiesclavagiste, favorable à la circulation des marchandises et des sciences et à l'expansion des idées issues des Lumières, cette colonisation conçue comme une œuvre de civilisation devait s'étendre à l'Afrique tout entière.

2 La deuxième partie de ce numéro porte sur l'ouvrage De l'Allemagne, dont on célèbre le bicentenaire en 2014. Intitulé «De l'Allemagne (1814-2014). Une mémoire au présent», ce volet s'ouvre sur une rapide étude de la réception de l'œuvre jusqu'à nos jours, par Marie-Claire HOOCK-DERMALE (pp. 95-103), puis Florence LOTTERIE (pp. 105-111), dans un texte au titre évocateur Jeter un pont sur l'abîme: (re)lectures allemandes de "De l'Allemagne", offre une présentation synthétique des contributions d'auteurs allemands qui composent le dossier. Kurt KLOOCKE (pp. 113-132) présente deux importantes études que Villers consacra en 1814 à De l'Allemagne: dans un compte rendu et l'introduction pour une édition de l'ouvrage chez le libraire Brockhaus, l'écrivain reconnaît dans la pensée de celle qui fut longtemps son amie ses propres théories énoncées en particulier dans sa Philosophie de Kant. S'il estime qu'elle n'a pas parfaitement saisi la philosophie et les mœurs allemandes, il partage sa perception des divergences qui opposent Français et Allemands et la rejoint dans sa conception de la nation et des liens que celle-ci entretient avec la littérature, tout comme dans la conviction que la compréhension et l'accueil de la culture de l'autre favorisent le progrès des deux pays. Bien moins élogieuse est la recension de De l'Allemagne par Jean-Paul, qu'étudie Gérard R. KAISER (pp. 133-145): pour Jean-Paul, un sentiment de vanité nationale et de supériorité aristocratique empêchent chez les Français et l'auteur de De l'Allemagne le développement d'une véritable empathie, seule apte à transmettre la culture allemande de manière authentique. En analysant l'échec de l'«amazone de l'esprit», Jean-Paul expose sa propre conception de la critique littéraire, qui repose sur la recherche d'une singularité esthétique et l'«idée d'une rencontre passionnée et sans violence avec ce qui est étranger en tant que tel». L'article suivant nous permet encore de mieux comprendre les réticences qui accompagnèrent la réception de l'ouvrage en Allemagne: en confrontant la représentation que De l'Allemagne offre du caractère allemand à celle 
de Schlegel, Jochen STROBel (pp. 147-163) montre comment Mme de Staël décrit les spécificités d'une nation figée dans un présent déjà dépassé, tandis que le critique la conçoit dans une perspective historique et évolutive, et l'envisage essentiellement dans les liens qu'elle entretient avec les autres pays d'Europe. Olaf MÜLLER (pp. 165-186), dans un bel article intitulé «L'air et les poêles ne conviennent ni à ma santé, ni à celle de ma fille». La naissance de "De l'Allemagne" et les traditions littéraires de l'exil, rappelle que Germaine de Staël publia son texte pour la première fois en 1813, alors qu'elle était en exil, et redonne toute son importance à ce contexte en dévoilant l'usage stratégique que l'écrivain en fit. Enfin Axel BLAESCHKE (pp. 187-197) présente son édition critique de De l'Allemagne, qui paraîtra dans le cadre des Euvres complètes de Mme de Staël en cours de publication chez Slatkine. Ce volume s'achève sur un in memoriam d'Othenin d'Haussonville, signé par Michel Delon. Le rapprochement des thématiques abordées, qui mêlent toutes deux poétique et politique, permet de mettre l'accent sur la question des représentations de l'altérité au sein du groupe de Coppet, et en ce qui concerne plus particulièrement Mme de Staël, sur la fragilité des frontières entre altérité et identité. 